\title{
APPLICATION OF WIWEDEMEN- FRANZE -LORANZE LAW TO INVESTIGATE THE EFFECT OF TEMPERATURE AND SECTION THICKNESS ON THE THERMAL CONDUCTIVITY OF DUCTILE GRAPHITE CAST IRON
}

\author{
Omar Elmabrouk \\ Department of Industrial and Manufacturing System Engineering, \\ Garyounis University, Benghazi, Libya
}

\begin{abstract}
A direct resistance measurement method using two point probes has been used to measure the electrical resistance of ductile graphite cast iron produced at different thickness sections and over a wide range of temperatures. The thermal conductivity of this type of cast iron was estimated using the Wiwedemen- Franze -Loranze Law. It was found that smaller section thickness has lower thermal conductivity than medium and larger thicknesses. This is due to the formation of compacted and degenerated ductile cast iron at higher section thicknesses.

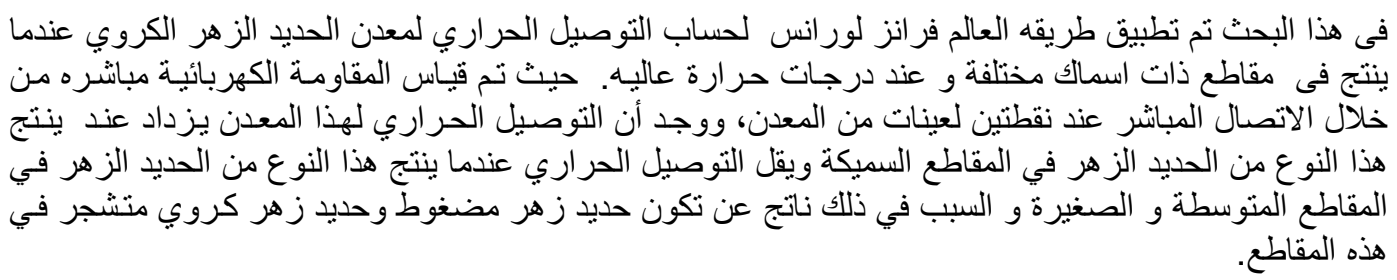

Keywords: Electrical resistance, thermal conductivity, ductile graphite iron.

\section{INTRODUCTION}

In some applications, such as cylinder heads, pistons, and brake drums, thermal conductivity is the main reason for the material selections. Cast irons have been used in such applications, since it combine good mechanical and friction property as well as $h$ good thermal conductivity [1].

The thermal conductivity of all cast iron appears to be controlled by the form, amount, and distribution of graphite [2].Because of the different interconnected network of the graphite particles in compacted graphite iron, its thermal conductivity is only slightly lower than that of grey iron, but much higher than that of ductile iron .[ 3 ]. Thermal conductivity values of metallographic phases of cast iron are presented in Table 1 . It can be seen that ferrite has higher thermal conductivity than pearlite and also that cementite can lower the cast iron thermal conductivity. [4].Typical values of thermal conductivity of different gray and ductile iron grades are presented Tables 2 and 3 for evaluated temperatures. For grey irons, thermal conductivity decreases with temperature. This trend is observed in many reports $[5,6,7,8]$, although there is no discussion on the cause of this behavior.

Relatively, few studies have been reported on the electrical conductivity at elevated temperature, since the measurements are extremely difficult, and it's difficult to measure thermal conductivity of metals and alloys precisely. In this paper we present the results of electrical conductivity of ductile compacted and flake cast iron and estimate the thermal conductivity of these types of cast iron over a wide range of temperatures.

\section{EXPERIMENTAL PROCEDURE}

\subsection{Material and Processing}

Ductile irons was produced in a step block casting in green sand with $5,10,20,40, \mathrm{~mm}$ thick steps as illustrated in Fig. 1. Sorel white cast iron and steel scrap were used as basic charge material. FeSiMgCermish metal used as an agent material, $\mathrm{Cu}$ and, $\mathrm{FeSi}$ were used as an alloying element, $0.5 \% \mathrm{FeSi}$ was used as post inoculation. The chemical composition of these materials is shown in Table 4.

\subsection{Melting Procedure}

Once the charge materials, Sorel and Steel scrap, prepared and calculated, they were melted down using a 10-17 kg capacity induction furnace installed with a clay graphite crucible. After having molten metal, alloying materials such as $\mathrm{Cu}$, and $\mathrm{FeSi}$ were added to the molten charge. In the stage of spheroidizing treatment, FeSiMgCerium Misch metal was added by plunging method with the plunger ladle shown in Fig. 2. The treatment temperature varied in the range of 1425 to $1475{ }^{\circ} \mathrm{C}$. Post inoculation was accomplished by adding $75 \%$ foundry grade ferrosilicon (lump size are in between 1-2 mm) from 
the top of the molten metal in the ladle. The molten metal was stirred to ensure complete solution and reaction inoculation. The treatment time and post inoculation time were 5 to 7 minute and 1.5 minute respectively. The pouring temperatures were in the range of 1400 to $1420{ }^{\circ} \mathrm{C}$. In order to understand the specimen belongs to which section thicknesses, codes were given to the samples. The sample codes are shown in Table 5.

\subsection{Sample Preparation and Optical Microscopy Studies}

The metallographic specimen was cut from each section of the stepped block. Specimens were prepared by using abrasive emery papers and were polished on METASERV universal polisher Equipment. The specimens were machined to the dimension shown in Fig. 3 and examined by optical microscope. The microphotographs were taken by NIKON OPTIPHOT.

\subsection{Electrical and Thermal Conductivity}

The variation of thermal conductivity of each specimen with temperatures gradient ranging from room temperatures to $500{ }^{0} \mathrm{C}$ was found via measuring electrical resistance.
The two point probe measurement technique shown in Fig. 4 was used for high temperature measurements.

The used set up is similar to the one used by M.Ali AKBAŞ [10], but, in this set up instead of using Nano voltmeter the digital voltmeter is equipped .This sep up consists of $30 \mathrm{~cm}$ long and 1.2 $\mathrm{cm}$ in dimeter alumia tube with closed bottom as the main part. Figure 5 shows the scheme of the specimen fixing mechanism used in high temperature resistivity measurements. In this tube there is window close to the bottom which used for changing the specimen.An alumina spaghetti in bottom of the tube was fixed by an alumina cement. Another spaghetti which was able to move up and down was attached to the open end by using a special mechanism made from brass.

The samples to be measured were placed between these two sapghtties and a pressure was applied to get better contacts.Utilizing this mechanism, it was possible to measure resistance of specimens simply by pumping $1 \mathrm{~A}$ constant current throught the Pt$\mathrm{Pt} / 13 \% \mathrm{Rh}$ wires and detecting the potenial drop in the specimen by means of Pt wires.

Table 1, Thermal conductivity of main metallographic phases of cast irons at room temperature [8]

\begin{tabular}{|l|c|c|c|}
\hline Metallographic constituent & \multicolumn{2}{|c|}{ Thermal conductivity, $\mathrm{W}$ m- ${ }^{\circ} \mathrm{C}-1$} \\
\hline & $0-100^{\circ} \mathrm{C}$ & $500^{\circ} \mathrm{C}$ & $1000{ }^{\circ} \mathrm{C}$ \\
\hline Ferrite & $71-80$ & 42 & 29 \\
\hline Pearlite & 50 & 44 & - \\
\hline Cementite & $7-8$ & - & - \\
\hline Graphite & - & $84-126$ & $42-63$ \\
\hline Parallel to basal plane & $293-419$ & - & - \\
\hline Perpendicular to basal plane & 84 & - & - \\
\hline
\end{tabular}

Table 2, Results of thermal conductivity for different grades of gray Iron [7]

\begin{tabular}{|c|c|c|c|c|c|c|}
\hline Temperature (C) & \multicolumn{7}{|c|}{ Thermal conductivity (W/K.m) } \\
\hline & GJL 150 & GJL 200 & GJL 250 & GJL 300 & GJL 350 & GJL 400 \\
\hline 100 & 52,5 & 50,8 & 48,8 & 47,4 & 45,7 & 44,0 \\
\hline 200 & 51,5 & 49,8 & 47,8 & 46,4 & 44,7 & 43,0 \\
\hline 300 & 50,5 & 48,8 & 46,8 & 45,4 & 43,7 & 42,0 \\
\hline 400 & 49,5 & 47,8 & 45,8 & 44,4 & 42,7 & 41,0 \\
\hline 500 & 48,5 & 46,8 & 44,8 & 43,4 & 41,7 & 40,0 \\
\hline
\end{tabular}

Table 3 Results of thermal conductivity for ductile irons [9]

\begin{tabular}{|c|c|c|c|c|c|c|}
\hline & GGG-35.3 & GGG-40 & GGG-50 & GGG-60 & GGG-70 & 4 Si-Mo \\
\hline $100^{\circ} \mathrm{C}$ & 40.2 & 38.5 & 36.0 & 32.9 & 29.8 & 25.1 \\
\hline $200^{\circ} \mathrm{C}$ & 43.3 & 41.5 & 38.8 & 35.4 & 32.0 & 27.2 \\
\hline $300^{\circ} \mathrm{C}$ & 41.5 & 39.8 & 37.4 & 34.2 & 31.0 & 28.1 \\
\hline $400^{\circ} \mathrm{C}$ & 38.8 & 37.4 & 35.3 & 32.8 & 30.3 & 28.6 \\
\hline $500^{\circ} \mathrm{C}$ & 36.0 & 35.0 & 33.5 & 31.6 & 29.8 & 28.9 \\
\hline
\end{tabular}


Omar Elmabrouk, "Application of Wiwedemen- Franze -Loranze Law to Investigate the Effect of ..."

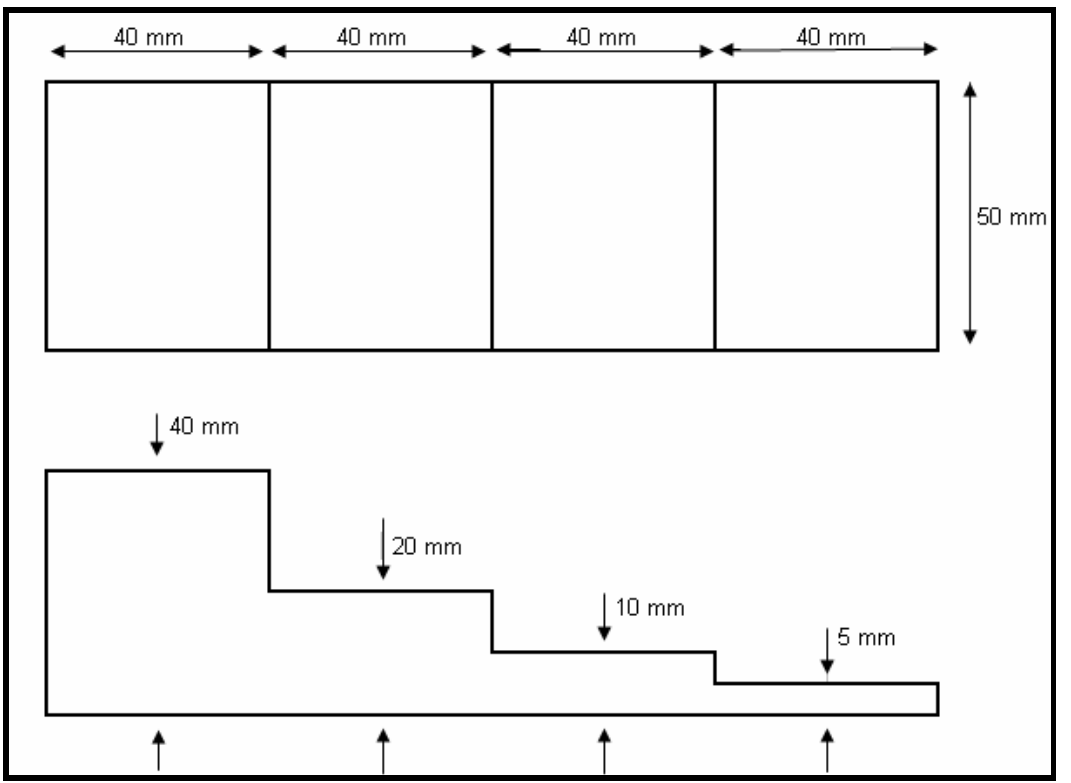

Fig.1 Step block with 5, 10, 20 and $40 \mathrm{~mm}$ thick steps

Table 4, Chemical composition of charge material.

\begin{tabular}{|c|c|c|c|c|c|c|c|c|c|c|c|}
\hline Charge Material & $\% \mathrm{C}$ & $\% \mathrm{Si}$ & $\% \mathrm{Mg}$ & $\% \mathrm{Ca}$ & $\% \mathrm{Al}$ & $\% \mathrm{RE}$ & $\% \mathrm{~V}$ & $\% \mathrm{~S}$ & $\% \mathrm{P}$ & $\% \mathrm{Cu}$ & $\% \mathrm{Fe}$ \\
\hline Sorel white cast iron & 4,3 & 0,2 & & & & & 0,2 & 0,02 & 0,02 & & Blance \\
\hline Steel & 0,2 & 0,2 & & & & & 0,3 & 0,02 & 0,07 & & Blance \\
\hline Scrap & & & & & & & & & & & \\
\hline $\mathrm{FeSiMgCe}$ & & $44-48$ & $55-65$ & 6 & Max 12 & 25 & & & & & Blance \\
\hline Misch metal & & & & & & & & & & & \\
\hline $\mathrm{FeSi}$ & & 75 & & 0,8 & & & & & & & Blance \\
\hline $\mathrm{Cu}$ & & & & & & & & & & Pure & \\
\hline $\begin{array}{l}\text { Post } \\
\text { İnoculation }\end{array}$ & & 75 & & & & & & & & & Blance \\
\hline
\end{tabular}

Table 5 Descriptions of Cods

\begin{tabular}{|c|l|}
\hline Code & \multicolumn{1}{|c|}{ Descriptions } \\
\hline 1 & Mg/S ratio 6.5 \\
$\mathrm{A}$ & Trail made by using FeSiMg-Cermish metal \\
$\mathrm{d}$ & $5 \mathrm{~mm}$ section thickness \\
$\mathrm{e}$ & $10 \mathrm{~mm}$ section thickness \\
$\mathrm{f}$ & $20 \mathrm{~mm}$ section thickness \\
$\mathrm{g}$ & $40 \mathrm{~mm}$ section thickness \\
\hline
\end{tabular}

Example: $1 \mathrm{Ag}$ is a sample taken from $40 \mathrm{~mm}$ section thickness of the heat of FeSiMg- Cermish metal treatments in which the ratio of $\mathrm{Mg} / \mathrm{S}$ is 6.5 . 
Omar Elmabrouk, "Application of Wiwedemen-Franze -Loranze Law to Investigate the Effect of ..."

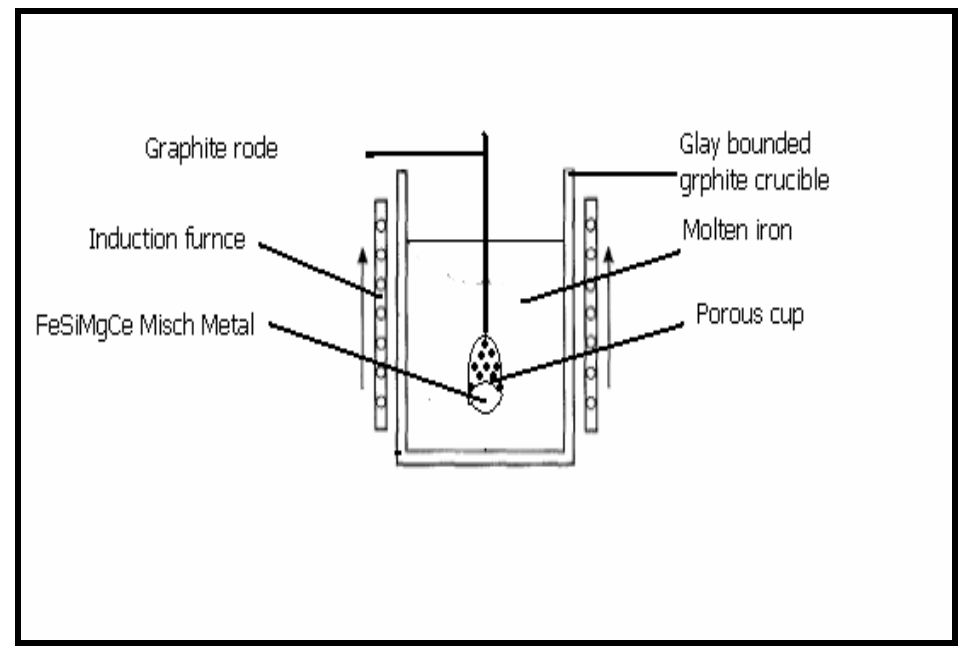

Fig. 2 Plunger Ladle Techniques

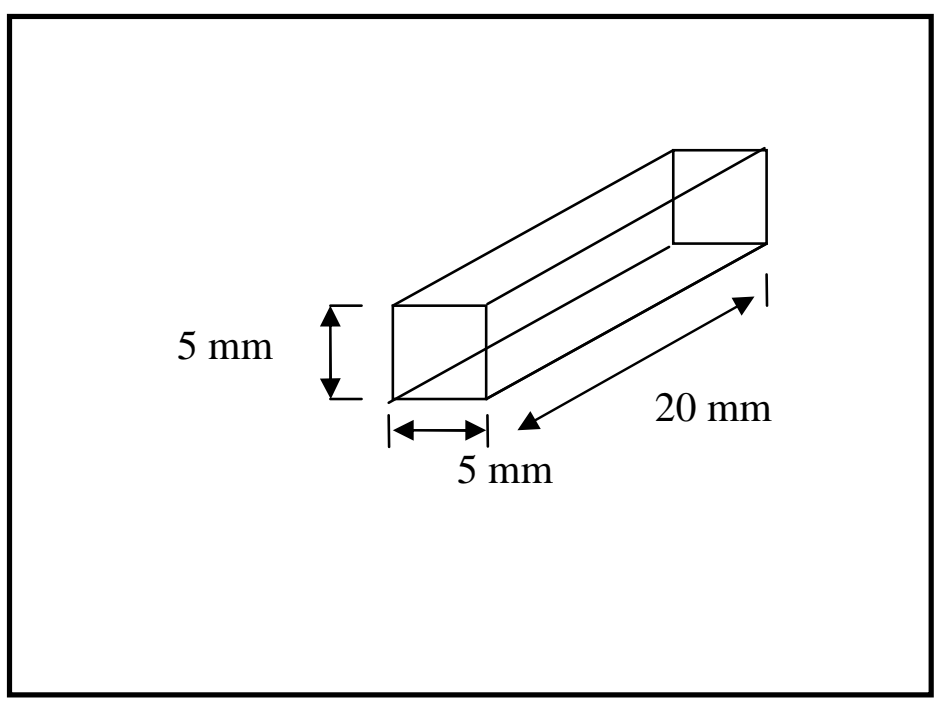

Fig. 3 Electrical resistivity specimen

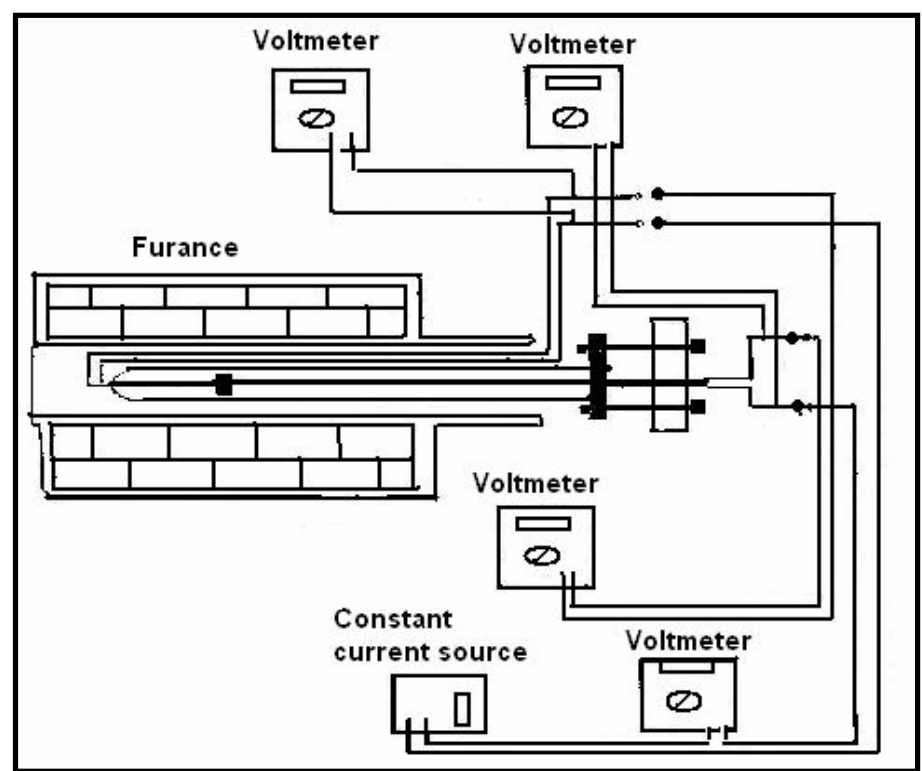

Fig. 4 The setup used for electrical resistance measurements [3] 


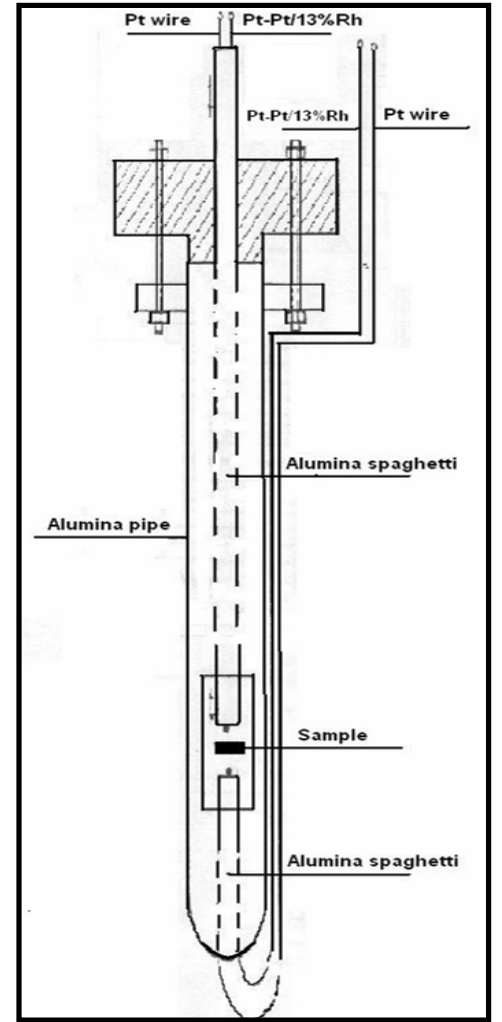

Fig. 5 The scheme of the specimen fixing mechanism used in high temperature resistance measurments [3]

As it's well known, the free electrons are primarily responsible for the electrical and thermal conductivity of metals and alloys; therefore, the Wiedemann-Franz-Loranz Law can be applied to relate the thermal conductivity to the electrical resistivity as follows.

$$
\frac{\lambda \rho_{e}}{T}=\frac{\pi^{2} K^{2}}{3 e^{2}}=L_{0}
$$

Where $\lambda_{\text {is }}$ the thermal conductivity, $\mathrm{T}$ is the absolute temperature. $\rho_{e}$ is the electrical resistivity, $\mathrm{K}$ is the Boltzman constant and $\mathrm{e}$ is the electron charge

The constant

$$
L_{0}=\frac{\pi^{2} K^{2}}{3 e^{2}}=2.445 \times 10^{-8} w \Omega K^{-2}
$$

The electrical resistance $(\mathrm{R})$ and electrical resistivity $\left(\rho_{e}\right)$ are

$$
R=\frac{\rho_{e} L}{A}
$$

Where $\mathrm{L}$ and $\mathrm{A}$ are the length and the crosssection area of specimen Therefore,

$$
\lambda=\frac{2.445 \times 10^{-8} \times T \times L}{R \times A}
$$

\section{RESULTS AND DİSCUSSION}

At spheriodizing potential, $\mathrm{Mg} / \mathrm{S}$ ratio equal to 6.5 and with the chemical composition shown in Table 6, the graphite shape was spheroidal in the small section and spheroidal with degenerated graphite in the medium and large section. Figures 6 through 9 show the microstructures of sections varying from 5 to 40 $\mathrm{mm}$. The electrical resistance of each section was measured; the results are shown in Table 7.

Figures 10 present the variation of thermal conductivity of ductile cast iron estimated by Wiedemann-Franz-Lorenz Law with temperature for 1Ad, e, f.

After presenting the results, it is seen that there is a good agreement between these results with the results from the literature; however the small variaitons can be attributed to the contact problem between the samples and the themocauples. This contact is becoming week especialy at high temperatures resulting in increasing the electrical resistance and then decreasing the thermal conductivity.

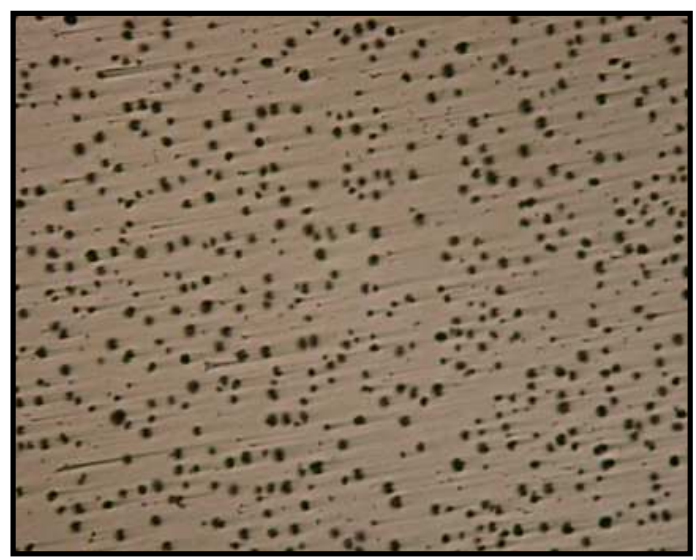

Fig. 6 Microstructure of specimen

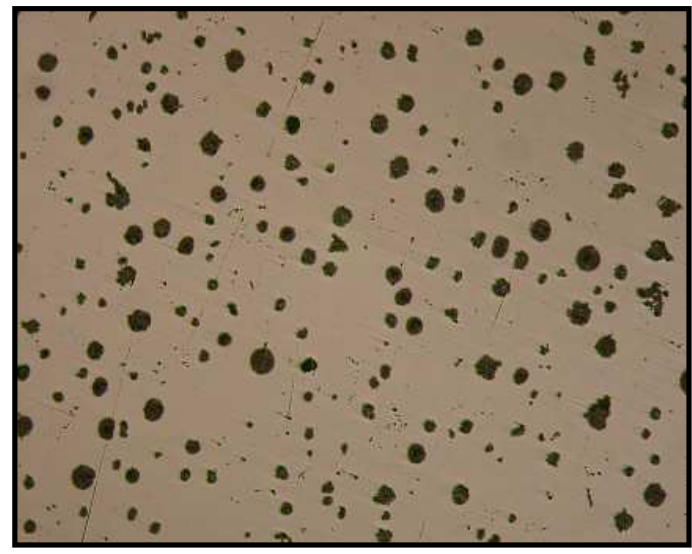

Fig. 7 Microstructure of specimen with 1Ad code. Magnification $\times 100$ with 1 Ae code. Magnification $\times$ 100 
Omar Elmabrouk, "Application of Wiwedemen- Franze -Loranze Law to Investigate the Effect of ..."

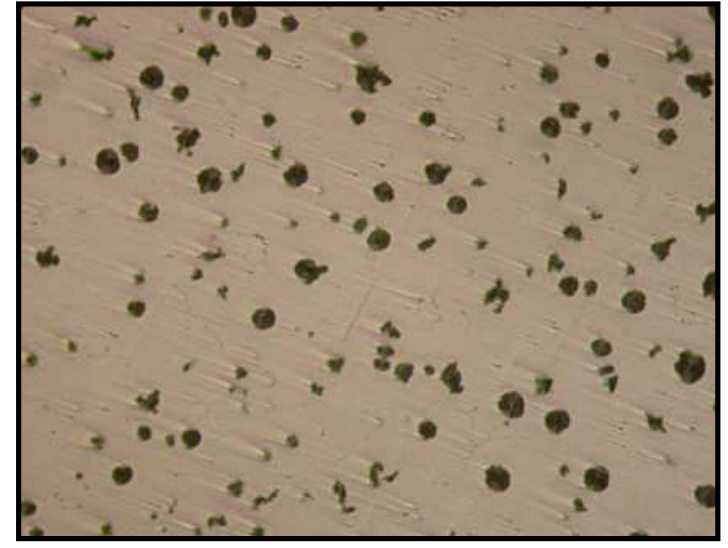

Fig. 8 Microstructure of specimen

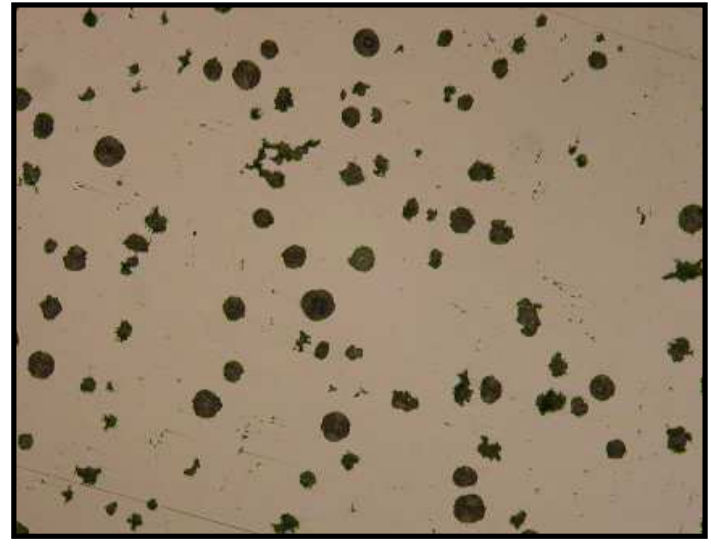

Fig. 9 Microstructure of specimen with 1Af code. Magnification $\times 100$ with $1 \mathrm{Ag}$ code .Magnification $\times 100$

Table 6 Chemical composition

\begin{tabular}{|c|c|c|c|c|c|c|c|c|}
\hline$\% \mathrm{Si}$ & $\% \mathrm{C}$ & $\% \mathrm{Mg}$ & $\% \mathrm{Cu}$ & $\% \mathrm{~S}$ & $\% \mathrm{Mn}$ & $\% \mathrm{P}$ & $\% \mathrm{Cr}$ & $\% \mathrm{CerMM}$ \\
\hline 2.757 & 3.755 & 0.066 & 0.798 & 0.0108 & 0.017485 & 0.000886 & 0.00024165 & 0.090818363 \\
\hline
\end{tabular}

Table 7, The Electrical Resistance of 1A heat

\begin{tabular}{|c|c|c|c|c|}
\hline $\begin{array}{c}\text { Temperature } \\
(\mathrm{K})\end{array}$ & $\begin{array}{c}\text { Resistance of } \\
1 \mathrm{Ad}(\Omega)\end{array}$ & $\begin{array}{c}\text { Resistance of } \\
1 \mathrm{Ae}(\Omega)\end{array}$ & $\begin{array}{c}\text { Resistance of } \\
1 \mathrm{Af}(\Omega)\end{array}$ & $\begin{array}{c}\text { Resistance of } \\
1 \mathrm{Ag}(\Omega)\end{array}$ \\
\hline 298 & & & & 0,000201 \\
\hline 323 & 0,000204 & 0.000203 & 0,00023 & 0,000222 \\
\hline 373 & 0,000234 & 0.000233 & 0,000257 & 0,000253 \\
\hline 423 & 0,000264 & 0.000266 & 0,000289 & 0,000279 \\
\hline 473 & 0,000294 & 0.000292 & 0,000316 & 0,000308 \\
\hline 523 & 0,000321 & 0.000321 & 0,000347 & 0,000338 \\
\hline 573 & 0,000355 & 0.000351 & 0,000377 & 0,000365 \\
\hline 623 & 0,000383 & 0.000375 & 0,000404 & 0,000395 \\
\hline 673 & 0,000414 & 0.00041 & 0,00043 & 0,000422 \\
\hline 723 & 0,000441 & 0.000438 & 0,000457 & 0,000447 \\
\hline 773 & 0,000467 & 0.000461 & & \\
\hline
\end{tabular}

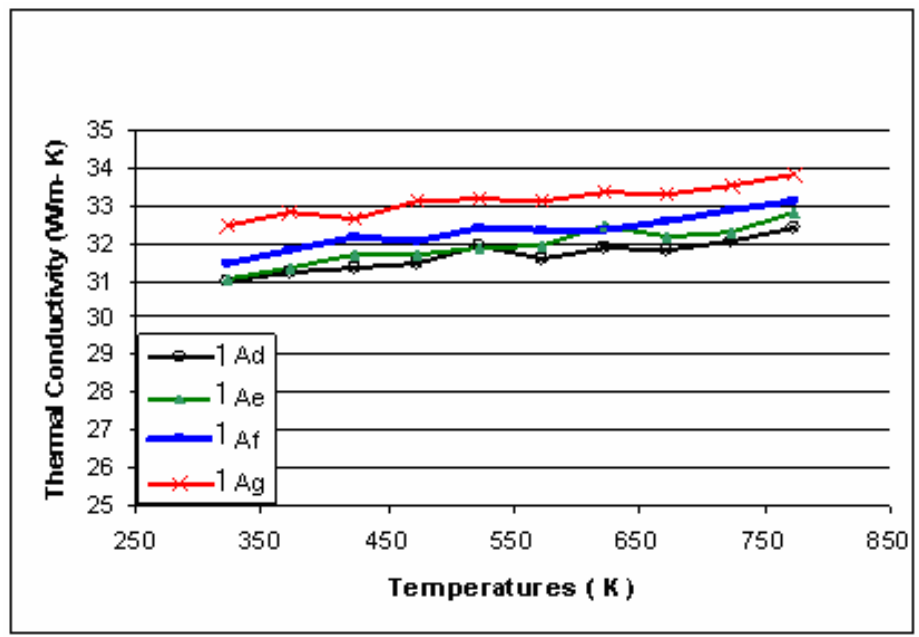

Fig. 10 Variation of thermal conductivity of $1 \mathrm{Ad}, \mathrm{e}, \mathrm{f}$ and $\mathrm{g}$ with temperature 
Omar Elmabrouk, "Application of Wiwedemen- Franze -Loranze Law to Investigate the Effect of ..."

\section{CONCLUSION}

The result showed that, the ductile cast iron has highest thermal conductivity at larger thickness followed by intermediate thicknesses, smaller thicknesses exhibits the lowest thermal conductivity. This is due to the presence of compacted and degenerated graphite cast iron.

\section{REFERENCES}

[1] W. L. Guesser, I. Masiero, E. Melleras, C. S. Cabezas UDESC, "Thermal Conductivity of Gray Iron and Compacted Graphite Iron Used for Cylinder Heads", Revista Matéria, v. 10, n. 2 , pp. 265 - 272, Junho de 2005

[2] Gürolhan Yaşar,"Compacted / Vermicular Graphite Production Techniques and The section Sensitivity of Compacted /Vermicular Graphite." M.S thesis, METU. , 1996

[3] James P. Hrusovsky," Factors Effecting Graphite Morphology, Matrix Structures and tensile properties of Compacted Graphite Cast Iron, Ph.D. Thesis, Case Western Reserve University, 1982
[4] HASSE, S., Duktiles Gusseisen. Schiele \& Schön, Berlin, 1996.

[5] ANGUS, H.T., "Cast Iron: Physical and Engineering Properties", BCIRA, pp. 126-134, 1960.

[6] "Thermal Conductivity of Unalloyed Cast Iron", BCIRA Broadsheet 203, 1981.

[7] Gusseisen mit Lamellengraphit - Eigenschaften und Anwendung. Konstruiren + Giessen, Zentrale für Gussvervendung. VDI-Verlag, Düsseldorf, 2000.

[8] STEFANESCU, D., "Physical Properties of Cast Iron", In: GOODRICH, G.M., Iron Casting Engineering Handbook, AFS,2003

[9] Gusseisen mit Kugelgraphit, Konstruiren + Giessen. Zentrale für Gussvervendung, VDIVerlag, Düsseldorf, 1988.

[10] M.Ali AKBAŞ,”Effect of Ni and Ti Substitution on the Superconducting Properties of YBa2Cu307-X System.” M.S thesis, METU. , 1991. 